\title{
A minimum 8-year follow-up comparative study of decompression and coflex stabilization with decompression and fusion
}

\author{
XIAOQING ZHENG $^{1 *}$, ZHIDA CHEN ${ }^{2 *}$, HONGLONG YU ${ }^{3 *}$, JIANXIONG ZHUANG $^{1}$, \\ $\mathrm{HUI} \mathrm{YU}^{1}$ and YUNBING $\mathrm{CHANG}^{1}$ \\ ${ }^{1}$ Department of Orthopaedics, Guangdong Provincial People's Hospital, Guangzhou, Guangdong 510030; \\ ${ }^{2}$ Department of Orthopaedics, The 909th Hospital of People's Liberation Army, \\ The Affiliated Southeast Hospital of Xiamen University, \\ Orthopedic Center of People's Liberation Army, Zhangzhou, Fujian 363000; \\ ${ }^{3}$ Department of Biomedical Engineering, Hefei University of Technology, Hefei 230009, P.R. China
}

Received November 18, 2019; Accepted March 11, 2021

DOI: $10.3892 /$ etm.2021.10027

\begin{abstract}
The current study aimed to compare the outcomes of decompression and interlaminar stabilisation with those of decompression and fusion for the treatment of lumbar degenerative disease (LDD) at a minimum 8-year follow-up. The current study also aimed to analyse the risk factors of radiographic adjacent segment degeneration (ASD). A total of 82 consecutive patients with LDD who underwent surgery between June 2007 and February 2011 were retrospectively reviewed. Of these patients, 39 underwent decompression and Coflex interspinous stabilisation (Coflex group) and 43 underwent decompression and posterior lumbar interbody fusion (PLIF) (PLIF group). All patients had a minimum of 8-years of follow-up data. Radiographic and clinical outcomes were compared between the groups, and the risk factors of developing radiographic ASD were also evaluated. The Oswestry disability index and visual analogue scale leg and back pain scores of both groups significantly improved compared with the baseline (all $\mathrm{P}<0.05$ ), and no difference were indicated between the two groups at each follow-up time point ( $\mathrm{P}>0.05)$. The Coflex group exhibited preserved mobility $(\mathrm{P}<0.001)$, which was associated with a decreased amount of blood loss $(\mathrm{P}<0.001)$, shorter duration of surgery $(\mathrm{P}=0.001)$, shorter duration of hospital stay and a lower incidence of ASD (12.8 vs. $32.56 \%$; $\mathrm{P}=0.040$ ) compared with the fusion group.
\end{abstract}

Correspondence to: Professor Yunbing Chang or Dr Hui Yu, Department of Orthopaedics, Guangdong Provincial People's Hospital, 106 Zhongshan Second Road, Guangzhou, Guangdong 510030, P.R. China

E-mail: cybspine@outlook.com

E-mail: yuhuijm@gmail.com

Abbreviations: ASD, adjacent segment degeneration; LDD, lumbar degenerative disease; ODI, Oswestry disability index; PLIF, posterior lumbar interbody fusion; VAS, visual analogue scale

Key words: decompression, fusion, interlaminar stabilisation, lumbar degenerative disease, adjacent segment degeneration
The current study indicated that coflex and fusion technologies are safe and effective for the treatment of LDD, based on long-term follow-up data. However, Coflex interspinous stabilisation was revealed to reduce ASD incidence. Under strict indications, Coflex interspinous stabilisation is an effective and safe treatment method.

\section{Introduction}

Lumbar degenerative disease (LDD) is a common disease in adults, often causing lower back pain and leg pain that frequently requires surgery (1). Decompression with or without spinal fusion has been thought to be the 'gold standard' for the treatment of LDD (2-4). To prevent the instability caused by wide decompression, instrumented spinal fusion is recommended (5-7). However, rigid fixation and fusion pose inherent problems, including greater invasiveness, longer surgical time and higher blood loss, and may cause adjacent segment degeneration (ASD) (8-11).

To address the limitations and disadvantages associated with fusion, novel techniques and implants with motion preservation, such as an interlaminar device, have been designed to provide segmental stability following decompression (12). A Coflex interlaminar device (Paradigm Spine) was designed to overcome the adverse effects of fusion (13). This device focuses on decelerating the degenerative process through dynamic stabilisation of the lumbar spine to provide adequate stability for restoring normal segmental kinematics, which allows for more physiological load transmission $(14,15)$. A number of previous studies have suggested that Coflex interspinous stabilisation is safe and efficacious $(16,17)$.

However, the majority of previous studies have only investigated the short-term results of Coflex with decompressive surgery. Whether Coflex interspinous stabilisation reduces the incidence of ASD compared with fusion requires further study with long-term follow-up data. Therefore, the purpose of the current retrospective study was to compare the radiographic and clinical outcomes between patients who underwent Coflex interspinous stabilisation and those who underwent decompression and fusion (PLIF) for single-level LDD and had a 
minimum follow-up time of 8 years. This was performed in order to investigate whether Coflex interspinous stabilisation affects the incidence of ASD, and to determine the risk factors for ASD in each group.

\section{Materials and methods}

Study design. The current study is a retrospective, comparative, single-institute study of two surgical procedures for the treatment of LDD with instability. The present study was approved by the Medical Research Ethics Committee of the Guangdong Provincial People's Hospital. The patients were well informed of the details of the study and signed an informed consent.

Patient selection. Between June 2007 and February 2011, a total of 82 patients (51 males, 31 females; mean age, $59.70 \pm 5.97$ years) with LDD treated with decompression and Coflex interspinous stabilisation (Coflex group; 39 patients; 23 males, 16 females; mean age, $58.79 \pm 6.46$ years) or decompression and PLIF (PLIF group; 43 patients; 28 males, 15 females; mean age, $60.51 \pm 5.43$ years) in Guangdong Provincial People's Hospital were retrospectively reviewed. The inclusion criteria were as follows: Aged 40-70 years and follow-up duration of at least 8 years; patients who complained of significant low back pain; radiating leg pain with or without neurogenic claudication; radiographic confirmation of no segmental instability at the adjacent segments; stable degenerative spondylolisthesis up to Meyerding grade II (18), lumbar spinal stenosis or lumbar disc herniation, or both. The exclusion criteria were as follows: History of lumbar spine surgery; damage of the vertebral body in the affected segment (for example, osteoporotic compression fracture or tumours), degenerative lumbar scoliosis $\left(>25^{\circ}\right)$, body mass index (BMI) $>40 \mathrm{~kg} / \mathrm{m}^{2}$, cauda equina syndrome, spinal infection or two or more segments requiring treatment.

Operative technique. All procedures were performed under general anaesthesia, and patients were placed in the prone position. The surgical segment was located using radiography.

In the Coflex group, a median incision $\sim 4-6 \mathrm{~cm}$ long was performed. Paraspinal muscles were separated subperiosteally, keeping the supraspinous ligament intact and exposing the bilateral facet joints to perform bilateral partial laminectomy. Undercutting facetectomy was performed carefully until freely movable nerve roots were identified. Microdiscectomy was performed if disk herniation was present. The supraspinous ligament was cut with a knife over the lower spinous process and reflected upwards, thereby separating it from both spinous processes, and the intervening interspinous ligament was excised to insert an optimal size of the Coflex spacer. The wings were subsequently tightened with a clamp, and the supraspinous ligament was re-sutured.

In the PLIF group, an 8-10 $\mathrm{cm}$ median incision was performed to expose the spinous process and both laminae. The ligamentum flavum and interspinous ligaments were subsequently removed, and the spinous process and laminae were resected to expose the entire nerve root and intervertebral space. Adequate decompression was performed, and an appropriately sized polyetheretherketone cage filled with an autograft bone was implanted into the intervertebral space and fixed with a pedicle screw system.
Clinical evaluation. The Oswestry disability index (ODI), $100 \mathrm{~mm}$ visual analogue scale (VAS)-back pain and VAS-leg pain (6) were compared to assess the clinical outcomes preoperatively, at 1,2 and 5 years, and at the final follow-up at $\geq 8$ years. The ODI recovery rate represented the degree of normal functioning after surgery and was calculated as follows: (postoperative ODI score-preoperative ODI score)/preoperative ODI score $\mathrm{x} 100 \%$. The degree of recovery was as follows: Excellent, $<50 \%$ improvement; good, improvement between 25 and $50 \%$ in ODI; fair, change of -25 to $+25 \%$ in ODI; poor, decrease of $>25 \%$ in ODI. A decrease of $>20 \mathrm{~mm}$ in VAS was considered a significant improvement. For each patient, , the operative time, amount of blood loss and post-treatment complications were also compared.

Radiological evaluation. The range of motion (ROM), posterior disk height (PDH), and foraminal height (FH) of the operated segment and the upper and lower adjacent segments were measured prior to surgery, at 1,3 and 5 years after surgery, and at the final follow-up at $\geq 8$ years (Fig. 1). As all patients underwent MRI as a routine examination preoperatively and at follow-up visits, the progression of disk degeneration was evaluated by the Pfirrmann classification (18). The following radiologic changes indicated ASD: Disk height reduced to $\geq 50 \%$, vertebral slip increased to $\geq 3 \mathrm{~mm}$ on neural lateral radiograph, and angulation of flexion versus extension $>10^{\circ}$ (19). A total of two experienced surgeons team evaluated the radiographs, and were also involved in the treatments of the patients. The examination was repeated twice to avoid intra-observer variations.

Statistical analysis. Unpaired t-test and $\chi^{2}$ or Fisher's exact test were used to compare all clinical and radiographic data. Differences in incidence rates of ASD and complications among the groups were evaluated using a $\chi^{2}$ test. Multivariable correlation analysis was used to analyse the risk factors for developing radiographic ASD. All data are presented as means \pm standard deviation. SPSS version 21.0 (IBM Corp.) was used for all statistical analyses. $\mathrm{P}<0.05$ was considered to indicate a statistically significant difference.

\section{Results}

Demographic and baseline clinical characteristics. The Coflex group was composed 39 patients of 23 men and 16 women, with a mean age of $58.79 \pm 6.46$ years. The follow-up duration was $104.24 \pm 7.23$ months. The PLIF group was composed 43 patients of 28 men and 15 women, with a mean age of $60.51 \pm 5.43$ years. The follow-up duration was $104.16 \pm 7.20$ months. No significant difference was identified in age, sex, BMI, follow-up time, preoperative foraminal height, operated segment ROM, duration of symptom, PDH, Pfirrmann grade of disk degeneration, VAS scores for leg and back pain or ODI scores between the two groups (all $\mathrm{P}>0.05$; Table I). The mean duration of surgery, amount of blood loss, and duration of hospital stay were significantly decreased in the Coflex group than in the fusion group (all $\mathrm{P}<0.05$; Table I).

Clinical outcomes. The ODI scores and VAS scores for back and leg pain markedly improved compared with the baseline scores in both groups at each follow-up time point (Fig. 2F-H). However, 
Table I. Demographic data.

\begin{tabular}{|c|c|c|c|}
\hline Variable & Coflex group $(n=39)$ & PLIF group $(n=43)$ & P-value \\
\hline Age (years) & $58.79 \pm 6.46$ & $60.51 \pm 5.43$ & 0.161 \\
\hline Sex (male/female) & & & 0.567 \\
\hline Male & 23 & 28 & \\
\hline Female & 16 & 15 & \\
\hline Duration of symptom (months) & $9.85 \pm 2.92$ & $10.40 \pm 3.37$ & 0.175 \\
\hline $\mathrm{BMI}\left(\mathrm{kg} / \mathrm{m}^{2}\right)$ & $23.42 \pm 0.84$ & $23.58 \pm 0.92$ & 0.349 \\
\hline Follow-up time (months) & $104.24 \pm 7.23$ & $104.16 \pm 7.20$ & 0.676 \\
\hline Preoperative posterior disc height (mm) & $6.53 \pm 1.05$ & $7.01 \pm 1.12$ & 0.387 \\
\hline Preoperative foraminal height & $19.67 \pm 2.62$ & $19.74 \pm 2.37$ & 0.255 \\
\hline Preoperative operated segment $\mathrm{ROM}\left({ }^{\circ}\right)$ & $6.81 \pm 2.79$ & $7.21 \pm 2.76$ & 0.516 \\
\hline Preoperative Pfirrmann grade & & & 0.492 \\
\hline II & 10 & 14 & \\
\hline III & 29 & 29 & \\
\hline Preoperative VAS leg pain score (mm) & $65.38 \pm 14.48$ & $67.21 \pm 14.36$ & 0.833 \\
\hline Preoperative VAS back pain score (mm) & $70.00 \pm 12.14$ & $67.91 \pm 13.72$ & 0.089 \\
\hline Preoperative ODI score & $61.59 \pm 9.81$ & $62.86 \pm 10.23$ & 0.754 \\
\hline Operative time (min) & $54.59 \pm 9.93$ & $100.49 \pm 24.17$ & 0.001 \\
\hline Blood loss (ml) & $81.67 \pm 18.58$ & $188.37 \pm 45.05$ & $<0.001$ \\
\hline Duration of hospital stay (days) & $5.56 \pm 1.33$ & $7.95 \pm 1.02$ & 0.026 \\
\hline
\end{tabular}

All data are presented as means \pm standard deviation. t-test and $\chi^{2} /$ Fisher's exact test were used to compare all clinical and radiographic data. BMI, body mass index; ROM, range of motion; VAS, visual analogue scale; ODI, Oswestry disability index.

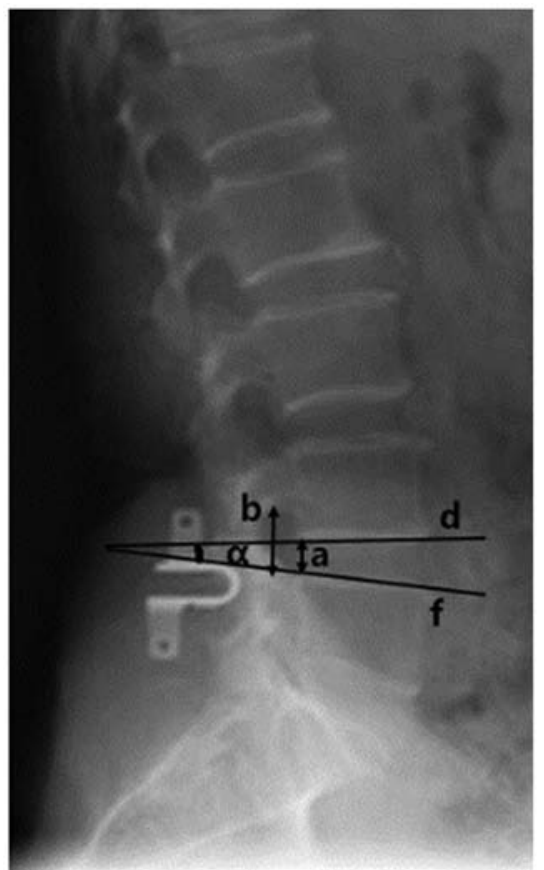

Figure 1. Radiological indices are presented at lateral views. a, Posterior disc height. $b$, Foraminal height. $\alpha$, intervertebral angle (range of motion $=$ extension $\alpha$ - flexion $\alpha$ ); $d$, line of inferior margin of upper vertebrae; $f$, line of superior margin of lower vertebral.

no significant difference was indicated in the scores between the two groups at each follow-up time point (Fig. 2F-H). It was demonstrated that ODI scores at 3 and 5 years postoperatively and at the final follow-up were markedly lower than the ODI score at 1 year postoperatively in the Coflex group, whereas no significant changes were noted at 3 and 5 years postoperatively and at the final follow-up in the Coflex group (Fig. 2F). In the PLIF group, the ODI scores at 3 and 5 years postoperatively and at the final follow-up were significantly lower than the ODI score at 1 year postoperatively, whereas no marked changes were noted between 3 and 5 years postoperatively and at the final follow-up (Fig. 2F). At 3 and 5 years postoperatively and the final follow-up, the VAS scores for back and leg pain decreased significantly compared with those at 1 year in the Coflex group (Fig. 2G and H), whereas no significant changes at 3 and 5 years postoperatively and at the final follow-up was observed in the Coflex group (Fig. 2G and H). In the PLIF group, the VAS scores for back and leg pain at 3 and 5 years postoperatively and at the final follow-up decreased markedly compared with those at 1 year postoperatively (Fig. $2 \mathrm{G}$ and $\mathrm{H}$ ), whereas no significant changes at 3 and 5 years postoperatively and at the final follow-up were observed (Fig. $2 \mathrm{G}$ and $\mathrm{H}$ ). The recovery ratio in ODI score and improvement in VAS scores for leg and back pain exhibited good results in both groups at the final follow-up, and no differences were indicated in the scores at baseline and in the last follow-up between the two groups (Table II).

Radiographic outcomes. The FH at baseline and at the final follow-up were not markedly different between the two groups (Table II; Fig. 2A), and no marked difference was identified between the scores at baseline and at the final follow-up (Fig. 2A). At baseline, no marked difference was demonstrated in the PDH between the two groups (Fig. 2B). In both two groups, the PDH at 
Table II. Clinical and radiographic outcomes at the final follow-up.

\begin{tabular}{|c|c|c|c|}
\hline Variable & Coflex group $(\mathrm{n}=39)$ & PLIF group (n=43) & P-value \\
\hline ODI recovery ratio (\%) & & & 0.797 \\
\hline$>50$ & $35(89.74)$ & $37(86.05)$ & \\
\hline $25-50$ & $4(10.26)$ & $6(13.95)$ & \\
\hline$-25-25$ & 0 & 0 & \\
\hline$<-25$ & 0 & 0 & \\
\hline ODI score & $18.44 \pm 7.05$ & $19.30 \pm 6.40$ & 0.674 \\
\hline \multicolumn{4}{|l|}{ VAS score of leg pain (\%) } \\
\hline$>20 \mathrm{~mm}$ decrease & $37(94.87)$ & $40(93.02)$ & \\
\hline$\leq 20 \mathrm{~mm}$ decrease & $2(5.13)$ & $3(6.98)$ & \\
\hline VAS score of leg pain & $18.97 \pm 7.54$ & $20.93 \pm 7.81$ & 0.729 \\
\hline VAS score of back pain (\%) & & & 0.512 \\
\hline$>20 \mathrm{~mm}$ decrease & $37(94.87)$ & $38(88.37)$ & \\
\hline$\leq 20 \mathrm{~mm}$ decrease & $2(5.13)$ & $5(11.63)$ & \\
\hline VAS score of back pain & $18.79 \pm 7.18$ & $20.70 \pm 7.99$ & 0.336 \\
\hline Posterior disk height (mm) & $6.75 \pm 1.22$ & $7.51 \pm 1.35$ & 0.301 \\
\hline Foraminal height (mm) & $18.25 \pm 1.49$ & $19.79 \pm 1.91$ & 0.060 \\
\hline \multicolumn{4}{|l|}{$\operatorname{ROM}\left({ }^{\circ}\right)$} \\
\hline Operated segment & $5.01 \pm 2.15$ & $0.42 \pm 0.26$ & $<0.001$ \\
\hline Upper adjacent segment & $7.60 \pm 2.24$ & $8.63 \pm 2.11$ & 0.035 \\
\hline$>10^{\circ}(\%)$ & $1(2.56)$ & $7(16.28)$ & 0.037 \\
\hline Lower adjacent segment & $7.28 \pm 2.05$ & $8.03 \pm 2.82$ & 0.176 \\
\hline$>10^{\circ}(\%)$ & 0 & $2(4.65)$ & 0.495 \\
\hline
\end{tabular}

All data are presented as means \pm standard deviation. t-test and $\chi^{2} /$ Fisher's exact test were used to compare all clinical and radiographic data. ODI, Oswestry disability index; ROM, range of motion; VAS, visual analogue scale.

the final follow-up had no difference than that at baseline (Fig. 2B). Additionally, no marked difference was observed in the PDH between the two groups at the final follow-up (Table II; Fig. 2B).

No marked difference was indicated in the ROM of the operated segment at baseline between the two groups $(\mathrm{P}=0.516$; Table I; Fig. 2); however, the ROM decreased compared with the baseline after surgery in both groups (Fig. 2C). Moreover, the ROM of the operated segment in the Coflex group was markedly higher compared with the PLIF group at the final follow-up (Fig. 2C; Table II). At baseline, no marked difference was found in the ROM of the upper adjacent segment in both groups (Fig. 2D). The ROM of the upper adjacent segment markedly increased from baseline to the final follow-up in both groups (Fig. 2D). However, the ROM of the upper adjacent segment was markedly higher in the PLIF group than in the Coflex group at the final follow-up (Fig. 2D; Table II). The ROM of the lower adjacent segment also demonstrated no marked difference at baseline in both groups (Fig. 2E). However, in the PLIF group, values markedly increased from baseline to the final follow-up (Fig. 2E), whereas no marked changes was noted in the Coflex group (Fig. 2E). At the final follow-up, no marked difference in ROM of the lower adjacent segment was indicated between the two groups (Fig. 2E).

Complications. In the PLIF group, post-op, one patient had a transient neurological deficit, one patient had a hematoma, and two patients had dural tears. On the contrary, in the Coflex group, one patient had a transient neurological deficit and three patients had anterior thigh pain. However, none of the perioperative complications in either group were persistent. As for long-term complications, in the PLIF group, 14 patients were diagnosed with ASD. Of these patients, four were severely symptomatic and underwent a subsequent operation. In the Coflex group, five patients were diagnosed with ASD, while three of these patients were severely symptomatic and underwent re-surgery. A total of two patients underwent recurrence disc herniation of the operation segment in the Coflex group. At the last follow-up, six patients in the Coflex group developed bone resorption of the spinous processes and looseness of internal fixation. All of them had undergone PLIF reoperation. No significant difference in complication and resorption rates were indicated between the two groups (Table III).

Risk factor analysis of ASD. A total of 5 patients (12.82\%) in the Coflex group and 14 patients $(32.56 \%)$ in the PLIF group exhibited ASD at the final follow-up ( $\mathrm{P}=0.040$; Table IV). More upper adjacent segment (15/19) deteriorations than lower adjacent segment (4/19) deteriorations were observed in these patients. The proportion of patients who underwent reoperation for ASD was not significantly different between the groups $(\mathrm{P}=0.794$; Table IV). The Pfirrmann grades of 

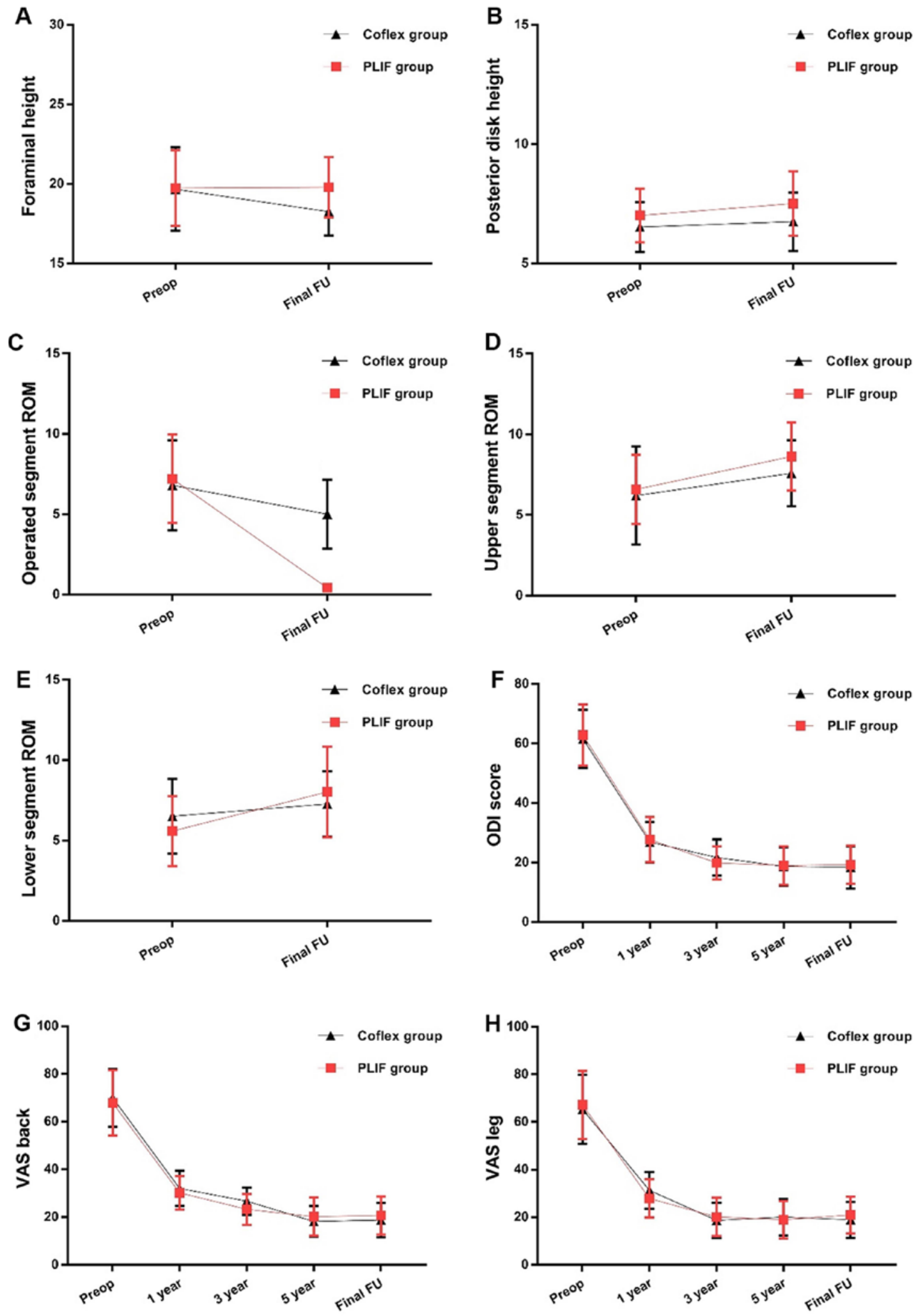

Figure 2. Clinical outcomes and radiologic outcomes. All data are presented as the means \pm standard deviation. A t-test was used to compare all clinical and radiographic data. (A) Foraminal height. (B) Posterior disc height. (C) ROM of the operated segment. (D) ROM of the upper adjacent segment. (E) ROM of the lower adjacent segment. (F) ODI score. (G) VAS back pain score. (H) VAS leg pain score. ROM, range of motion. ODI, Oswestry disability index; VAS, visual analogue scale; FU, follow-up.

both upper and lower adjacent segments were significantly different between the two groups $(\mathrm{P}<0.001$ and $\mathrm{P}=0.020$, respectively; Table IV). The results of the logistic regression analysis demonstrated that the surgical method and ROM were significant risk factors of ASD $(\mathrm{P}=0.031$ and $\mathrm{P}=0.021$, respectively; Table V). Fig. 3 presents a patient who underwent Coflex interspinous stabilisation had ASD in the lower adjacent segment. 
Table III. Complication and resorption rates in the Coflex and PLIF groups.

\begin{tabular}{lccr}
\hline Complication & Coflex group $(\mathrm{n}=39)$ & PLIF group $(\mathrm{n}=43)$ & P-value \\
\hline Current $(\%)$ & $4(10.26)$ & $4(9.30)$ & 0.999 \\
Long-term (\%) & $13(33.33)$ & $14(32.56)$ & 0.818 \\
Reoperation (\%) & $9(23.08)$ & $4(9.30)$ & 0.130 \\
\hline
\end{tabular}

All data are presented as means \pm standard deviation. $\chi^{2} /$ Fisher's exact test were used to compare all clinical data.

Table IV. Patients with ASD and Pfirrmann grade in the Coflex and PLIF groups at the final follow-up.

\begin{tabular}{|c|c|c|c|}
\hline Variable & Coflex group $(n=39)$ & PLIF group $(n=43)$ & P-value \\
\hline Number of ASD (\%) & $5(12.82)$ & $14(32.56)$ & 0.040 \\
\hline Upper adjacent segment & 4 & 11 & \\
\hline Lower adjacent segment & 1 & 3 & \\
\hline Disc height reduced $\geq 50 \%$ & 3 & 6 & \\
\hline Vertebral slip $\geq 4 \mathrm{~mm}$ & 2 & 4 & \\
\hline $\mathrm{ROM}>10^{\circ}$ & 1 & 9 & \\
\hline Reoperation for ASD (\%) & $3(7.69)$ & $4(9.30)$ & 0.794 \\
\hline Upper adjacent segment Pfirrmann grade & & & $<0.001$ \\
\hline$\leq \mathrm{III}$ & 23 & 9 & \\
\hline$\geq \mathrm{IV}$ & 16 & 34 & \\
\hline Lower adjacent segment Pfirrmann grade & & & 0.020 \\
\hline$\leq \mathrm{III}$ & 32 & 28 & \\
\hline$\geq \mathrm{IV}$ & 7 & 15 & \\
\hline
\end{tabular}

All data are presented as means \pm standard deviation. $t$-test and $\chi^{2} /$ Fisher's exact test were used to compare all clinical and radiographic data. ASD, adjacent segment degeneration; ROM, range of motion.

\section{Discussion}

In the current study, the clinical outcomes between Coflex interspinous stabilisation and fusion surgery alone were compared. The results demonstrated that Coflex interspinous stabilisation was able to reduce the incidence of ASD. The occurrence rate of ASD in the Coflex group (12.82\%) was significantly lower compared with the fusion group (32.56\%), and the Pfirrmann grade of both the upper and lower adjacent segments in the Coflex group was significantly lower than that in the fusion group at the final follow-up. Moreover, the results of the logistic regression analysis revealed that the surgical method and perioperative ROM were significant risk factors of ASD. These results revealed that Coflex interspinous stabilisation is more advantageous in decreasing the incidence of ASD than fusion surgery.

The PLIF is often considered to be the 'gold standard' treatment for LDD with instability following failure of conservative treatment (2). However, increased trauma, increased amount of blood loss and a high incidence of ASD after fusion surgery are receiving increased attention $(20,21)$. To reduce the incidence of serious complications that are associated with spinal fusion, motion-preserving devices, such as dynamic interspinous spacer devices, were developed $(10,22)$.

In the 1990s, Jacques Samani first invented the interspinous U-shaped fixture and demonstrated good results during clinical application (15). Furthermore, in 2005, Paradigm Spine improved the dynamic stabilisation device and named it Coflex, which can provide stability for the operated segment for unloading the facet joint and for maintaining the direct decompression effect (23). A level I study that was approved by the Food and Drug Administration directly assessed the outcome of Coflex interspinous stabilisation and demonstrated that Coflex interspinous stabilisation is an effective and sustainable treatment option for LDD and is not an inevitable precursor to fusion (16). A biomechanical study conducted by Kong et al (17) revealed that Coflex interspinous stabilisation with fusion could stabilise the transition segment and restrict flexion and extension of that segment. A study performed by Richter et al (24) involving a large sample of nearly 14,000 patients who underwent Coflex interspinous stabilisation demonstrated that the Coflex interlaminar device is a safe and viable option in the selection of instrumentation for spinal stabilisation. However, few convincing long-term follow-up clinical studies have compared the effectiveness and safety between Coflex interspinous stabilisation and fusion only in the treatment of LDD.

The results of the current study revealed that Coflex is able to provide comparable clinical outcomes to PLIF in the treatment of LDD with instability. All patients achieved significant improvement in ODI and VAS scores for leg and back pain compared with the baseline. Furthermore, Coflex interspinous stabilisation has 


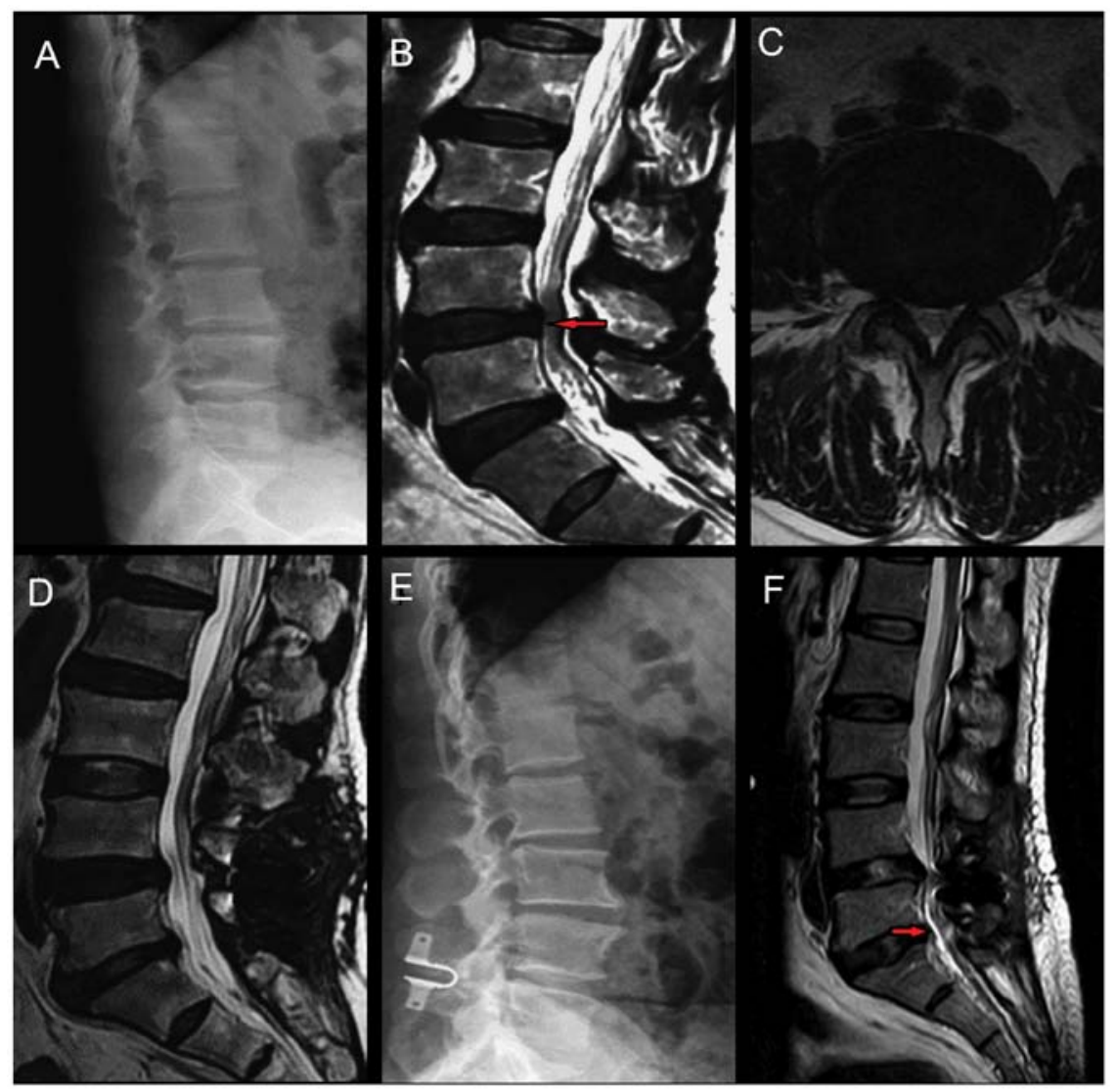

Figure 3. (A) Preoperative X-ray. (B-C) Preoperative MRI indicates LDD at L4-5 (red arrow). (D-E) One year postoperatively. (F) MRI indicates ASD in lower adjacent segment at the final follow-up. ASD, adjacent segment degeneration; LDD, lumbar degenerative disease.

Table V. Risk factors for developing radiographic ASD.

\begin{tabular}{lrrr}
\hline & $\begin{array}{c}\text { No ASD } \\
(\mathrm{n}=63)\end{array}$ & $\begin{array}{c}\text { ASD } \\
(\mathrm{n}=19)\end{array}$ & P-value \\
Variable & & & 0.031 \\
Surgical method & 34 & 5 & \\
$\quad$ Coflex & 29 & 14 & \\
Fusion & & & 0.929 \\
Age (years) & 12 & 3 & \\
$<55$ & 51 & 16 & \\
$\geq 55$ & & & 0.302 \\
Sex & 39 & 12 & \\
Male & 24 & 7 & \\
Female & & & 0.807 \\
BMI (kg/m $\left.{ }^{2}\right)$ & 57 & 18 & \\
$\geq 25$ & 6 & 1 & \\
$<25$ & & & 0.021 \\
Perioperative ROM $\left(^{\circ}\right)$ & 61 & 16 & \\
$\leq 10^{\circ}$ & 2 & 3 & \\
$>10^{\circ}$ & & & 0.442 \\
Perioperative Pfirmann grade & 22 & 2 & \\
II & 41 & 17 & \\
III & & & \\
\hline
\end{tabular}

Multivariable correlation analysis was used to analyse the risk factors for developing radiographic ASD. ASD, adjacent segment degeneration; BMI, body mass index; ROM, range of motion. been indicated to present a number advantages over PLIF, such as shorter operative time, decreased amount of blood loss and shorter duration of hospital stay, due to the minimally invasive nature of Coflex implantation. Furthermore, Coflex interspinous stabilisation requires less laminar resection and does not necessitate interbody fusion. The exposure of the transverse process and facet joints to reduce damage to the paraspinal muscles was not necessary during Coflex implantation. These results are similar to those of a previous study (19). A randomised controlled trial demonstrated that Coflex interspinous stabilisation can provide comparable clinical outcomes with lumbar fusion surgery in the treatment of LDD after a 5-year follow-up (21). Furthermore, a previous study has also demonstrated the advantages in terms of perioperative outcomes, such as shorter length of hospital stay, decreased amount of blood loss and shorter operative time, over fusion (10). In a retrospective study by Yuan et al (21), no significant difference was indicated between VAS and ODI improvements during a minimum 5-year follow-up between the Coflex and PLIF groups. Errico et al (25) also conducted a retrospective study of 127 patients and revealed that Coflex implantation markedly relieved back and leg pain for at least 5 years. In the current study, similar results were observed, indicating that patients who underwent Coflex interspinous stabilisation achieved significantly improved clinical outcomes after a minimum 8-year follow-up, which were comparable with those with PLIF. These findings indicated that both groups had similar and satisfactory clinical outcomes.

The results of the present study demonstrated that the $\mathrm{FH}$ at baseline and at the final follow-up was not significantly 
different between the two groups. The PDH in both groups was maintained and with no significant difference compared with the baseline at the final follow-up. A previous study revealed that Coflex interspinous stabilisation significantly increased the FH and PDH at the implanted segment in the immediate postoperative period or at the 1-year follow-up (21). However, in the current study, the FH and PDH were decreased and close to the baseline value at the final follow-up. The results suggested that the FH and PDH were well preserved after a minimum 8-year follow-up in the Coflex group, which were comparable with the findings in the PLIF group. Reduction of ROM at the implanted segment has been frequently reported in previous studies $(20,21,26)$. Davis et al (26) demonstrated that the ROM at the implanted segment decreased significantly at 24 months postoperatively. Yuan et al (21) demonstrated that the ROM at the adjacent segments in the Coflex group had no significant changes, whereas the ROM at the superior adjacent segment in the PLIF group was significantly increased. Furthermore, the ROM of the implanted segment in the Coflex group was significantly improved compared with the PLIF group at the final follow-up. The results of the aforementioned study were similar to the results of the current study, demonstrated that ROM decreased significantly at the implanted segment in both groups, whereas greater preservation of motion was observed in the Coflex group. However, the present study indicated that the ROM in the adjacent segment was significantly increased at the final follow-up in the PLIF group. These postoperative ROM changes are considered to be an advantage of Coflex interspinous stabilisation compared with fusion, as a higher degree of ROM changes at the adjacent segments may lead to ASD.

ASD has been a significant problem in clinical practice after spinal fusion. Alentado et al (20) reported that reoperation accounts for $9 \%$ of patients who developed ASD after undergoing fusion surgery. Previous studies have confirmed that the degeneration of intervertebral disk nucleus cells was an intrinsic factor in the development of ASD $(27,28)$, whereas the increased disk pressure was an important stimulative factor for accelerating the development of ASD (29). A biomechanical study indicated that increased stress and ROM of adjacent segments were the most important factors causing and accelerating the development of ASD (23). Although previous studies have investigated the risk factors for ASD progression (19,30-32), the precise pathogenesis of ASD remains uncertain. Additionally, the logistic regression analysis demonstrated that the surgical method was a significant risk factor of ASD. The results of the current study revealed that Coflex interspinous stabilisation decreases the incidence of ASD compared with fusion surgery. The results also indicated that the preoperative ROM of the implanted segment was another significant risk factor of ASD. This was caused by the need to compensate for the hypermobility of the adjacent segment after fusion. Furthermore, a larger preoperative ROM of the implanted segment indicated that adjacent segments need to compensate more. Previous biomechanical and clinical studies have explained the compensatory loading transfer (33) and increased ROM (34-36) at adjacent levels after rigid fixation.

Although other complications such as postoperative nausea, vomiting, nerve root injury and internal fixation system fractures were also reported in previous studies, no significant differences were indicated in the results of these studies $(10,21,25)$. The incidence of complications in the current study is consistent with reports in the previous literature $(10,21,25)$. Comfortable and strict indication is important when choosing Coflex interspinous stabilisation. Additionally, the Coflex interlaminar device should be placed deep enough between the interlaminar spaces because insufficient implantation depth would increase stress on the spinous process. This may cause spinous process bone resorption, device fixation loosening and possibly a spinous process fracture.

The current study was retrospective without randomisation in patient selection, which may generate bias. Although the cost of the treatment is not free in China, it was not considered to be a factor in the current study, which may be a limitation. Additionally, the mean duration of follow-up was slightly longer than 8 years, and an extended follow-up study is currently being conducted. The sample size was also relatively small, although it exceeded the size for detecting a statistical difference in clinical outcomes. A randomised controlled trial with a large sample size is warranted in the future to increase the reliability of the clinical results.

The present study demonstrated that decompression and Coflex interspinous stabilisation can achieve satisfactory and comparable long-term clinical outcomes to PLIF in the treatment of LDD. Coflex stabilisation can preserve the mobility of the operated segment with lesser amount of blood loss, shorter operative duration and shorter length of hospital stay, compared with PLIF. Furthermore, Coflex stabilisation can significantly decrease the incidence of ASD compared with PLIF. The results of the current study suggested that Coflex stabilisation is an acceptable alternative to PLIF for the treatment of LDD.

\section{Acknowledgements}

The authors would like to acknowledge Mr Hongwu Mao and Miss Weiran Ye (Pinghu Hospital Affiliated to Shenzhen University, Shenzhen, China) for their assistance in data collection. Dr Yong Xiao (Department of Neurosurgery, University Medicine Greifswald, Germany) assisted in the development of the radiographic data collection and measurement methods. The authors would also like to thank Dr Sascha Marx (Department of Neurosurgery, University Medicine Greifswald, Germany) for language modification.

\section{Funding}

No funding was received.

\section{Availability of data and materials}

The datasets used and/or analyzed during the current study are available from the corresponding author on reasonable request.

\section{Authors' contributions}

YC designed the experiments. XZ and ZC collected and interpreted the data. HoY and HuY collected the follow-up data. $\mathrm{XZ}, \mathrm{JZ}$ and HuY collected and analyzed the data, and wrote the manuscript. All authors read and approved the final version of the manuscript. 


\section{Ethics approval and consent to participate}

The Ethics Committee of the Guangdong Provincial People's Hospital approved the study protocol. Signed informed consent was obtained from all patients included in the study.

\section{Patient consent for publication}

Not applicable.

\section{Competing interests}

The authors declare that they have no competing interests.

\section{References}

1. Du Bois M, Szpalski M and Donceel P: Patients at risk for long-term sick leave because of low back pain. Spine J 9: 350-359, 2009

2. Brantigan JW, Neidre A and Toohey JS: The Lumbar I/F Cage for posterior lumbar interbody fusion with the variable screw placement system: 10-year results of a Food and Drug Administration clinical trial. Spine J 4: 681-688, 2004.

3. Harrop JS, Youssef JA, Maltenfort M, Vorwald P, Jabbour P, Bono CM, Goldfarb N, Vaccaro AR and Hilibrand AS: Lumbar adjacent segment degeneration and disease after arthrodesis and total disc arthroplasty. Spine (Phila Pa 1976) 33: 1701-1707, 2008

4. Lai PL, Chen LH, Niu CC, Fu TS and Chen WJ: Relation between laminectomy and development of adjacent segment instability after lumbar fusion with pedicle fixation. Spine (Phila Pa 1976) 29: 2527-2532, 2004.

5. Lin B, Yu H, Chen Z, Huang Z and Zhang W: Comparison of the PEEK cage and an autologous cage made from the lumbar spinous process and laminae in posterior lumbar interbody fusion. BMC Musculoskelet Disord 17: 374, 2016.

6. Pearson A, Blood E, Lurie J, Abdu W, Sengupta D, Frymoyer JW and Weinstein J: Predominant leg pain is associated with better surgical outcomes in degenerative spondylolisthesis and spinal stenosis: Results from the Spine Patient Outcomes Research Trial (SPORT). Spine (Phila Pa 1976) 36: 219-229, 2011.

7. Kleinstück FS, Grob D, Lattig F, Bartanusz V, Porchet F, Jeszenszky D, O'Riordan D and Mannion AF: The influence of preoperative back pain on the outcome of lumbar decompression surgery. Spine (Phila Pa 1976) 34: 1198-1203, 2009.

8. Imagama S, Kawakami N, Matsubara Y, Tsuji T, Ohara T, Katayama Y, Ishiguro $\mathrm{N}$ and Kanemura T: Radiographic adjacent segment degeneration at 5 years after L4/5 posterior lumbar interbody fusion with pedicle screw instrumentation: Evaluation by computed tomography and annual screening with magnetic resonance imaging. Clin Spine Surg 29: E442-E451, 2016.

9. Volkheimer D, Malakoutian M, Oxland TR and Wilke HJ: Limitations of current in vitro test protocols for investigation of instrumented adjacent segment biomechanics: Critical analysis of the literature. Eur Spine J 24: 1882-1892, 2015.

10. Musacchio MJ, Lauryssen C, Davis RJ, Bae HW, Peloza JH, Guyer RD, Zigler JE, Ohnmeiss DD and Leary S: Evaluation of decompression and interlaminar stabilization compared with decompression and fusion for the treatment of lumbar spinal stenosis: 5-year follow-up of a prospective, randomized, controlled trial. Int J Spine Surg 10: 6, 2016.

11. Hilibrand AS and Robbins M: Adjacent segment degeneration and adjacent segment disease: The consequences of spinal fusion? Spine J 4 (Suppl 6): 190S-194S, 2004.

12. Trautwein FT, Lowery GL, Wharton ND, Hipp JA and Chomiak RJ: Determination of the in vivo posterior loading environment of the Coflex interlaminar-interspinous implant. Spine J 10: 244-251, 2010.

13. Gala RJ, Russo GS and Whang PG: Interspinous implants to treat spinal stenosis. Curr Rev Musculoskelet Med 10: 182-188, 2017.

14. Kaner T, Sasani M, Oktenoglu T and Ozer AF: Dynamic stabilization of the spine: A new classification system. Turk Neurosurg 20: 205-215, 2010.

15. Sangiorgio SN, Sheikh H, Borkowski SL, Khoo L, Warren CR and Ebramzadeh E: Comparison of three posterior dynamic stabilization devices. Spine (Phila Pa 1976) 36: E1251-E1258, 2011.
16. Bae HW, Lauryssen C, Maislin G, Leary S and Musacchio MJ Jr: Therapeutic sustainability and durability of coflex interlaminar stabilization after decompression for lumbar spinal stenosis: A four year assessment. Int J Spine Surg 9: 15, 2015.

17. Kong C, Lu S, Hai Y and Zang L: Biomechanical effect of interspinous dynamic stabilization adjacent to single-level fusion on range of motion of the transition segment and the adjacent segment. Clin Biomech (Bristol, Avon) 30: 355-359, 2015.

18. Pfirrmann CW, Metzdorf A, Zanetti M, Hodler J and Boos N: Magnetic resonance classification of lumbar intervertebral disc degeneration. Spine (Phila Pa 1976) 26: 1873-1878, 2001.

19. Chen XL, GuanL, Liu YZ, Yang JC, Wang WLand Hai Y: Interspinous dynamic stabilization adjacent to fusion versus double-segment fusion for treatment of lumbar degenerative disease with a minimum follow-up of three years. Int Orthop 40: 1275-1283, 2016.

20. Alentado VJ, Lubelski D, Healy AT, Orr RD, Steinmetz MP, Benzel EC and Mroz TE: Predisposing characteristics of adjacent segment disease after lumbar fusion. Spine (Phila Pa 1976) 41: 1167-1172, 2016.

21. Yuan W, Su QJ, Liu T, Yang JC, Kang N, Guan L and Hai Y: Evaluation of Coflex interspinous stabilization following decompression compared with decompression and posterior lumbar interbody fusion for the treatment of lumbar degenerative disease: A minimum 5-year follow-up study. J Clin Neurosci 35: 24-29, 2017.

22. Lawrence BD, Wang J, Arnold PM, Hermsmeyer J, Norvell DC and Brodke DS: Predicting the risk of adjacent segment pathology after lumbar fusion: A systematic review. Spine (Phila Pa 1976) 37 (Suppl 22): S123-S132, 2012.

23. Tsai KJ, Murakami H, Lowery GL and Hutton WC: A biomechanical evaluation of an interspinous device (Coflex) used to stabilize the lumbar spine. J Surg Orthop Adv 15: 167-172, 2006.

24. Richter A, Schütz C, Hauck M and Halm H: Does an interspinous device (Coflex) improve the outcome of decompressive surgery in lumbar spinal stenosis? One-year follow up of a prospective case control study of 60 patients. Eur Spine J 19: 283-289, 2010.

25. Errico TJ,KamerlinkJR,QuirnoM,SamaniJandChomiakRJ:Survivorship of coflex interlaminar-interspinous implant. SAS J 3: 59-67, 2009.

26. Davis R, Auerbach JD, Bae H and Errico TJ: Can low-grade spondylolisthesis be effectively treated by either coflex interlaminar stabilization or laminectomy and posterior spinal fusion? Two-year clinical and radiographic results from the randomized, prospective, multicenter US investigational device exemption trial: Clinical article. J Neurosurg Spine 19: 174-184, 2013.

27. Soukane DM, Shirazi-Adl A and Urban JP: Computation of coupled diffusion of oxygen, glucose and lactic acid in an intervertebral disc. J Biomech 40: 2645-2654, 2007.

28. Galbusera F, van Rijsbergen M, Ito K, Huyghe JM, Brayda-Bruno $\mathrm{M}$ and Wilke HJ: Ageing and degenerative changes of the intervertebral disc and their impact on spinal flexibility. Eur Spine J 23 (Suppl 3): S324-S332, 2014.

29. Adams MA and Dolan P: Intervertebral disc degeneration: Evidence for two distinct phenotypes. J Anat 221: 497-506, 2012.

30. Mannion AF, Leivseth G, Brox JI, Fritzell P, Hägg O and Fairbank JC: ISSLS Prize winner: Long-term follow-up suggests spinal fusion is associated with increased adjacent segment disc degeneration but without influence on clinical outcome: results of a combined follow-up from 4 randomized controlled trials. Spine (Phila Pa 1976) 39: 1373-1383, 2014.

31. Yang JY, Lee JK and Song HS: The impact of adjacent segment degeneration on the clinical outcome after lumbar spinal fusion. Spine (Phila Pa 1976) 33: 503-507, 2008.

32. Zhu Z, Liu C, Wang K, Zhou J, Wang J, Zhu Y and Liu H: Topping-off technique prevents aggravation of degeneration of adjacent segment fusion revealed by retrospective and finite element biomechanical analysis. J Orthop Surg Res 10: 10, 2015.

33. Perez-Orribo L, Zucherman JF, Hsu KY, Reyes PM, Rodriguez-Martinez NG and Crawford NR: Biomechanics of a posterior lumbar motion stabilizing device: In vitro comparison to intact and fused conditions. Spine (Phila Pa 1976) 41: E55-E63, 2016.

34. Ghiselli G, Wang JC, Bhatia NN, Hsu WK and Dawson EG: Adjacent segment degeneration in the lumbar spine. J Bone Joint Surg Am 86: 1497-1503, 2004.

35. Kumar MN, Baklanov A and Chopin D: Correlation between sagittal plane changes and adjacent segment degeneration following lumbar spine fusion. Eur Spine J 10: 314-319, 2001.

36. Dong Y, Zheng X, Gu H, Liang G, Zhuang J, Liang CX, Liu B and Chang Y: Is the interspinous device (Coflex) outdated in the treatment of lumbar spinal stenosis? A seven-year follow-up. Spine Res 4: 2, 2018.

This work is licensed under a Creative Commons Attribution-NonCommercial-NoDerivatives 4.0 International (CC BY-NC-ND 4.0) License. 